\title{
AGRAVAMENTO DE EPILEPSIAS SOB TRATAMENTO
}

\author{
Michel Pierre Lison: \\ Jose Geraldo SPeciali **
}

O efeito indesejável mais conhecido das medicações antiepilépticas sobre as crises é o desencadeamento de manifestações de sentido oposto ao de seu campo de ação predominante. Menos vezes fodem precipitar o aparecimento de formas por elas geralmente atenuadas.

A relação entre epilepsias "malígnas" e tratamento antiepiléptico não foi objeto de estudos detalhados. Julgamos de interesse relatar nossas observações selecionadas entre as crianças epilépticas regularmente seguidas em nosso Serviço.

\section{A S U I S T I C A}

Caso 1 - A.M.T., sexo masculino, amarelo, nascido em novembro de 1964, (Reg. 76.358). Parto normal, a têrmo, pesando 2.250 g. Demorou para chorar; dificuldade respiratória nas primeiras horas de vida. Só pegou o seio após uma semana. Ictericia neonatal tratada com luz fluorescente.

Aos 8 meses, convulsão lateralizada à esquerda, durante periodo febril. Tratado com fenobarbital, $15 \mathrm{mg}$, o quadro repetiu-se com um ano de idade, novamente durante episódio febril. Fol instituida terapêutica com primidona (250 $\mathrm{mg}$ ) e fenobarbital (15 mg). Não apresentou manifestaçc̃es epilépticas até 1 ano e 7 meses quando, durante processo febril devido a amidalite, entrou em estado de mal hemitônico esquerdo. Fol hospitalizado, melhorando em três dias. Medicado com difenilhidantoina (100 $\mathrm{mg})$ e fenobarbital $(50 \mathrm{mg})$, passados três meses, apresentou crises atônicas mais freqüentes ao acordar, caracterizadas por queda da cabeça sobre o tronco. A substituição da hidantoina pela primidona (500 mg) não modificou o quadro, repetindo-se as crises em número superior a 20 por dia.

O desenvolvimento psicomotor mostrava discreto retardo: a criança falava pouco e caia freqüentemente. Apresentava discreta hemiparesia esquerda, principalmente no membro inferior.

No início de janeiro de 1967, o EEG revelou ponta-ondas lentas na região rolândica parassagital direita. A criança pasou a ser medicada com diazepam $(7,5 \mathrm{mg}$ por dia) mantendo-se o fenobarbital $(50 \mathrm{mg})$. Recebeu alta em 15 de fevereiro utili7.ando $20 \mathrm{mg}$ por dia de diazepam. Em poucos dias as crises foram controladas, desaparecendo as anomalias EEG paroxísticas. Em agosto, recebia $8 \mathrm{mg}$ de diazepam por dia. O EEG evidenciou recidiva das alterações focais.

Em setembro, estando febril, sofreu várias crises hemitônicas esquerdas e, em seguida, estado de mal de ausência controlado com a administração endovenosa de

Departamento de Neuropsiquiatria e Psicologia Médica da Faculdade de Medicina de Ribeirão Preto da Universidade de São Paulo (Prof. J. Armbrust-Figueiredo): * Professor Adjunto; * Auxiliar de Ensino. 
$7,5 \mathrm{mg}$ de diazepam. Passou bem durante três dias, surgindo depois crises atônicas generalizadas. Nos meses seguintes, apesar de aumentos sucessivos da dose de diazepam até $20 \mathrm{mg}$ por dia, foram observadas crises atônicas generalizadas e hemigeneralizadas a esquerda, crises hemiatônicas esquerdas e crises tônicas generalizadas. Os EEG evidenciaram ponta-ondas lentas difusas, irregulares e pseudorritmicas.

Caso 2 - A.B., sexo masculino, branco, nascido em julho de 1962 (Reg. 28.696). Parto normal, a têrmo. Desde os dois meses de idade, crises tônicas generalizadas, noturnas freqüentemente, com desvio conjugado dos globos oculares para a esquerda. Raramente passava a noite sem uma ou várias crises. Aos 8 meses de idade passou a receber $30 \mathrm{mg}$ de fenobarbital por dia. As crises reduziram-se a duas por mês em média. Acrescentado ulteriormente $20 \mathrm{mg}$ diários de difenil-hidantoina, nova melhora ocorreu, persistindo apenas algumas manifestações isoladas.

Até junho de 1964, o desenvolvimento psicomotor não mostrou alteraçōes. Em fins de julho de 1964, quando já não apresentava manifestações convulsivas, surgiu um quadro de astenia muscular, com hipotonia global associada a modificaçóes da atividade intelectual. A substituição da difenilhidantoina pela primidona (125 $\mathrm{mg}$ por día) não impediu o agravamento do quadro e, em outubro, o exame revelou hipotonia generalizada. A criança não sorria e não reconhecia seus familiares. O EEG revelou ponta-ondas lentas difusas. Internada, substituiu-se progressivamente a primidona pela trimetadiona $(600 \mathrm{mg}$ por dia), introduzindo-se ulteriormente etilmetilsuccinimida ( $250 \mathrm{mg}$ por dia). Houve melhora progressiva. Recebeu alta em inicio de novembro. Na semanas seguintes acentuou-se a melhora, desaparecendo a hipotonia, e, no EEG, as ponta-ondas lentas.

Em janeiro de 1966, após suspensão da trimetadiona houve recidiva do quadro hipotônico e das alterações mentais. Tratado com diazepam ( $8 \mathrm{mg}$ por dia) notou-se melhora considerável. Em julho a ocorrência de crises clônicas no membro inferior esquerdo e versão ocular ipsilateral justificou a suspensão do diazepam. Dias depois surgiram crises atônicas generalizadas. Desta época em diante foram notadas manifestaçōes convulsivas e nāo convulsivas, com ponta-ondas e poliponta-ondas lentas difusas, irregulares e pseudorritmicas.

Em 1972 persistiram algumas crises tônicas ao despertar e retardo do desenvolvimento psicomotor.

Aspectos clínicos e eletrencefalográficos pertinentes a parte da evolução deste caso foram objeto de publicação? ${ }^{2}$.

Caso 3 - J.R.P., sexo masculino, preto, nascido em 1962 (Reg. 60.118). Parto demorado. Falou com dois anos, não sendo registradas outras alteraçôes do desenvolvimento psicomotor. Com três anos de idade, crise hemiclónica esquerda dlurna. Até 1969 o mesmo tipo de crise repetiu-se 3 vezes durante o sono. Em fevereiro de 1969 ocorreu uma crise hemiclônica noturna à direita. A criança referia então numerosas crises paroxisticas de dor abdominal. Medicado com difenilhidantoina (100 mg por dia) e fenobarbital ( $50 \mathrm{mg}$ por dia), passou 4 meses sem manifestacão epiléptica. A ocorrência de uma crise tônica esquerda seguida por hemiparesia passageira justificou o aumento da dosagem de difenilhidantoina para $200 \mathrm{mg}$ por dia. Com essa medida surgiu ataxia. Reduzida a dosagem para $100 \mathrm{mg}$ por dia, recidivaram crises hemitônico-clônicas à esquerda. Três meses após o aumento da dosagem de difenilhidantoina para $150 \mathrm{mg}$ por dia houve piora do estado do paciente: deixou de falar e passou a apresentar agitação extrema, com auto e alo-agıessividade e desintcresse pelo ambiente. A suspensão da difenilhidantoina e o aumento do fenokarbital para $100 \mathrm{mg}$ não modificaram o quadro. Após 8 meses do quadro mental, o EEG evidenciou ponta-ondas lentas e rápidas irregulares, pseudorrítmicas e difusas.

A introdução de nitrazepam (15 mg por dia), fol seguida por melhora do comportamento e reaquisição da linguagem, não havendo melhora eletrencefalográfica. 
A ocorrência de crises tônicas generalizadas seguidas por clonias à esquerda motivou a introdução de clonazepam ( $3 \mathrm{mg}$ por dia). Com esta medida desapareceram as crises motoras e recidivaram os distúrbios de comportamento e de linguagem.

CASo 4 - S.R.M.O., sexo feminino, branca, nascida em 1969 (Reg. 119.923). Parto normal porém com discreta cianose. Com a idade de 1 ano e 7 meses apresentara nefrite, e, no $60^{\circ}$ dia da moléstia, hipotonia com cianose por cerca de uma hora. Passados dois dias, surgiram, ao despertar, crises tônicas generalizadas diárias, com taquipnéia e palidez, seguidas por período de uma a duas horas de medo intenso. Apareceram auto e alo-agressividade, diminuição no tempo de sono e terror noturno. Em janeiro de 1970 houve melhora das crises após a introdução de primidona e fenobarbital. A partir de maio de 1971 foram administrados $10 \mathrm{mg}$ de nitrazepam e $50 \mathrm{mg}$ de fenobarbital por dia, aumentando a freqüência das crises e melhorando o comportamento. O EEG revelou pontas isoladas ou agrupadas de projeção assincrona em áreas occipital esquerda e fronto-rolândico-parietais com polaridade positiva nas projeções anteriores e negativa nas rolândico-parieto-occiptais.

Em outubro de 1971 foram acrescentados $100 \mathrm{mg}$ de difenilhidantoina. Houve redução do número das crises. O EEG, em novembro, revelou ponta-ondas irregulares, de $3 \mathrm{c} /$ seg na região rolândico-parietal esquerda e pontas rolândicas isoladas à direita. Em dezembro substituiu-se o nitrazepam por clonazepam (três miligramas por dia), havendo controle das crises por dois meses e piora do comportamento. Em fevereiro e março de 1972, com o aumento da dose de difenilhidantoina para $200 \mathrm{mg}$ por dia, não ocorreram manifestações epilépticas mas, nos dois meses seguintes foram observadas 6 crises tónicas. Em julho apresentava ataxia e hipertrofia gengival. Ocorreram duas a três crises atônicas à direita por dia com queda ocasional. O EEG, em agosto, revelou atividade de fundo lenta, ponta-ondas, ponta-ondas agudas e lentas irregulares, pseudorritmicas e difusas predominando no hemisfério cerebral esquerdo. Suspensa a difenilhidantoina, as crises atonicas desapareceram em uma semana. O EEG, em fins de agosto, evidenciou ponta e ponta-ondas irregulares e difusas predominando na região rolândico-parietal esquerda. Em setembro foram registradas pontas, isoladas ou por surtos, nas regiōes fronto-rolândico-parietais e occipital esquerda.

CASo 5 - A.F.P., sexo feminino, branca, nascida em 1963 (Reg. 60.118). Aos 5 meses de idade, durante episódio febril, a paciente entrou em estado de mal epiléptico hemigeneralizado à esquerda, do qual resultou hemiplegia. Medicada com fenobarbital apresentou nova crise hemigeneralizada, em periodo febril, com um ano e meio. Com dois anos, estado de mal hemigeneralizado por três horas. Aos 4 anos recidiva das crises hemiclônicas ( 1 a 3 por mês). Medicada com difenilhidantoina e fenobarbital (100 mg por dia), houve ligeira melhora. Em dezembro de 1969 a freqüencia das crises aumentou, havendo dias com uma manifestação em seguida a outra. Em fevereiro de 1970, após suspensão na véspera da medicação antiepiléptica, apresentou quadro de astenla muscular, embotamento intelectual, incapacidade para sair do leito, com um dia de duração. Em fins de fevereiro o EEG evidenciava ponta-ondas rápidas fronto-rolândico-parietais à direita. Com a diminuiçāo da dosagem da difenilhidantoina e do fenobarbital para $50 \mathrm{mg}$ por dia e a introdução de 7,5 mg de nitrazepam diários, cessaram as crises. No início de março as anormalidades eletrencefalográficas desapareceram. Em agosto de 1971, ocorreu uma crise hemiclônica esquerda. Em setembro foram registradas pontas de projeçāo parieta! direita. Em outubro ocorreram três crises hemigeneralizadas. Até 1973 crises esporádicas foram observadas principalmente quando a criança deixava de tomar o fenobarbital e/ou a difenilhidantoina. 


\begin{tabular}{|c|c|c|c|c|c|c|c|}
\hline \multirow[b]{2}{*}{ Caso } & \multirow[b]{2}{*}{ Drogas } & \multirow[b]{2}{*}{ Idade } & \multicolumn{2}{|c|}{ Intervalos até a piora } & \multicolumn{2}{|c|}{ Primeiras manifestações da piora } & \multirow[b]{2}{*}{ Evolução } \\
\hline & & & do início & $\begin{array}{l}\text { da última } \\
\text { medicaçåo }\end{array}$ & clínicas & eletrencefalográficas & \\
\hline 1 & $\underset{\mathrm{F}}{\mathrm{DFH}}$ & 2 a. $2 \mathrm{~m}$ & 1 a. $6 \mathrm{~m}$ & $3 \mathrm{~m}$ & crises atônicas & $\begin{array}{l}\text { ponta-ondas lentas } \\
\text { localizadas }\end{array}$ & $\begin{array}{l}\text { Controle inicial. Recidiva. } \\
\text { Difusão das alterações } \\
\text { EEG. }\end{array}$ \\
\hline 2 & $\underset{\mathrm{DFH}}{\mathrm{F}}$ & 2 a. & 1 a. $10 \mathrm{~m}$ & 1 a. $3 \mathrm{~m}$ & $\begin{array}{l}\text { estado de mal de } \\
\text { ausência }\end{array}$ & $\begin{array}{l}\text { ponta-ondas lentas } \\
\text { difusas }\end{array}$ & $\begin{array}{l}\text { Controle inicial. } \\
\text { Recidiva. }\end{array}$ \\
\hline 3 & $\begin{array}{c}\text { DFH } \\
\text { F }\end{array}$ & 7 a. $10 \mathrm{~m}$ & 4 a. & $8 \mathrm{~m}$ & $\begin{array}{l}\text { quadro psicótico } \\
\text { (estado de mal crô- } \\
\text { nico de auséncia) }\end{array}$ & $\begin{array}{l}\text { ponta-ondas lentas } \\
\text { difusas }\end{array}$ & $\begin{array}{l}\text { Controle isolado das ma- } \\
\text { nifestacões não convulsi- } \\
\text { vas e convulsivas; nenhu- } \\
\text { ma melhora EEG. }\end{array}$ \\
\hline 4 & $\begin{array}{l}\text { DFH } \\
\text { F } \\
\text { Cl }\end{array}$ & 3 a. $4 \mathrm{~m}$ & 1 a. $9 \mathrm{~m}$ & $9 \mathrm{~m}$ & $\begin{array}{l}\text { crises hemiatônicas } \\
\text { diárias }\end{array}$ & $\begin{array}{l}\text { ponta-ondas lentas } \\
\text { predominando a } \\
\text { esquerda }\end{array}$ & $\begin{array}{l}\text { Controle clinico inicial; } \\
\text { desaparecimento ulterior } \\
\text { das ponta-ondas lentas. }\end{array}$ \\
\hline 5 & $\begin{array}{c}\mathrm{DFH} \\
\mathrm{F}\end{array}$ & 6 a. $6 \mathrm{~m}$ & 6 a. $1 \mathrm{~m}$ & 2 a. $6 \mathrm{~m}$ & $\begin{array}{l}\text { crises hemiclonicas } \\
\text { freqüientes }\end{array}$ & $\begin{array}{l}\text { ponta-ondas rápidas } \\
\text { difusas à direita }\end{array}$ & $\begin{array}{l}\text { Controle clinico e EEG } \\
\text { inicial. Recidiva parcial. }\end{array}$ \\
\hline
\end{tabular}

Quadro 1 -Drogas utilizadas e idade por ocasic̄o da piora e intervalos entre o início da síndrome epiléptica, introducão do último esquema terapêutico e piora. Resumo da evoluçâo clínico-eletrencefalográfica dos 5 pacientes. DFH $=$ difenilhidantoina; $\mathrm{F}=$ fenobarbital; $\mathrm{Cl}=$ clonazepam; $a=$ ano(s); $m=$ mês(es). 
COMENTARIOS

Pelos dados expostos no quadro 1 verifica-se ter havido agravamento do quadro epiléptico durante tratamento com a associação difenilhidantoina-fenobarbital. Tal associaç̃̃o não é a mais utilizada no tratamento de crianças epilépticas em nosso Serviço.

As primeiras manifestações epilépticas do agravamento foram diferentes das anteriormente apresentadas em 4 dos 5 pacientes; neles, a epilepsia convulsiva foi substituída for formas não convulsivas, generalizadas ou não, paroxísticas com inibição do tono muscular ou prolongadas com modificações do estado mental e/ou do tono muscular. Estas últ:mas manifestações correspondem à formas crônicas de estados de ausência de acordo com os critérios estabelecidos por Lugaresi e col. ${ }^{4}$. As modificaçc̃es clínicas e eletrencefalográficas do tipo conta-ondas lentas localizadas ou generalizadas observadas no início do agravamento são compative:s com a sindrome de Lennox-Gastaut.

A substituição da difenilhidantoina por primidona em dois pacientes não urovocou redução na freqüência das crises; contudo, a suspensão da hidantoina em outro, foi seguida por melhora clínica e, ulteriormente, eletrencefalográfica. A introdução de trimetadiona e de derivados benzodiazepínicos produziu melhora ou controle inicial do distúrbio. Tais fatos indicam que as novas manifestações epilépticas dependem do desequilíbrio entre os mecanismos cerebrais responsáveis pelas crises convulsivas e não convulsivas, possibilitado pelo uso prolongado de droga com ação predominantemente anticonvulsionante.

O recrudescimento das manifestações convulsivas com ponta-ondas rápidas no EEG do quinto paciente sob tratamento com a mesma associação, corresconderia a um efeito paradoxal. O aparecimento de quadro próximo do estado de ausência, astenia muscular, embotamento intelectual e incapac:dade para sair do leito após a suspensão da difenilhidantoina e o controle das crises convulsivas com droga de ação predominante sobre as manifestações não convulsivas são fatos quc se coadunam com tal hipótese.

A possibilidade de ação tóxica da difenilhidantoina por efeito cumulativo nāo parece plausível não somente pelas baixas dosagens utilizadas mas também pelo quadro clínico bastante diverso do observado nas chamadas encefalopatias difenilhidantoínicas (crises em opistótono e outras manifestações convulsivas, sinais neurológicos focais ${ }^{1,3}$ ).

A instalação definitiva de síndrome de Lennox-Gastaut em 3 dos 4 pacietes que apresentaram ponta-ondas evidencia o mau significado prognóstico de tal grafoelemento, mesmo quando localizado. $O$ único caso sem ponta-onda lenta por ocasião do agravamento evoluiu satisfatoriamente.

A incidência de crises epilépticas não convulsivas "malígnas" (atônicas, estados de mal crônicos e atípicos de ausência) e de ponta-ondas lentas em vez de manifestações de epilepsia generalizada não convulsiva comum com 
ponta-ondas rápidas parece depender da ocorrência de agressões cerebrais orgânicas e/ou funcionais múltiplas. Foram referidos prematuridade, ictericia nconatal e estado de mal hemiconvulsivo (caso 1 ) ; crises convulsivas freqüentes (caso 2); traumatismo de parto e retardo do desenvolvimento psicomotor (caso 3 ); cianose pós-natal e nefrite (caso 4). Nos três casos que evoluíram mal, surgiram crises convulsivas com a instalação do quadro polimorfo caracte. rístico da síndrome de Lennox.

Nossas observações demonstram que durante a administração de drogas predominantemente anticonvulsionantes em casos predispostos podem incidir criṣes não convulsivas com características clínicas e eletrencefalográficas malígnas, precursoras de epilepsia polimorfa e rebelde.

Enquanto o papel dessas drogas, em particular da associação fenobarbitaldifenilhidantoina, no desencadeamento de encefalopatias epilépticas graves da infância não for perfeitamente esclarecido, impõe-se o seguimento clínico e eletrencefalográfico cuidadoso de crianças com elevado número de crises e antecedentes de agressões cerebrais múltiplas e, eventualmente, a adoção de terapêutica com amplo campo de ação antiepiléptica.

\section{RES U M O}

Foram selecionadas 5 crianças que desenvolveram forma grave de epilepsia durante tratamento antiepiléptico. Destas, três apresentaram sindrome de Lennox irreversível. Todas estavam medicadas com a associação fenobarbitaldifenilhidantoina por ocasião do agravamento. As características clínicas e eletrencefalográficas dos pacientes no início da piora são compativeis com a instalação de distúrbio epiléptico de sentido oposto aos geralmente beneficiados pelas drogas utilisadas. As características malignas das novas formas de epilepsia estão provavelmente na dependência de agressões cerebrais pregressas, orgânicas e/ou funcionais.

\section{S U M M A R Y}

\section{Severe changes in seizure patterns during antiepileptic therapy}

The cases of five children with malign changes in seizure patterns during treatment with antiepileptic drugs are reported. Three patients developed irreversible Lennox syndrome. All the patients were treated by the association phenobarbital-diphenylhydantoin. The mechanism of the clinical and EEG modiifcations might be related to the development of an epileptic disturbance which has an opposite behaviour to those commonly improved by some antiepileptic drugs. The incidence of previous cerebral lesions is an important factors on the establishment of severe epileptic complications. 
R E F E R N C I A S

1. LEVY, L. L. \& FINICHEL, G. M. - Diphenylhydantoin activated seizures. Neurology (Minneapolis) 15:716, 1965.

2. LISON, M. P.; MOURA-RIBEIRO, M. V. \& MEGA, D. - Complicação rara e reversivel de síndrome convulsiva: hipotonia generalizada e alterações da atividade intelectual. Arq. Neuro-Psiquiat. (São Paulo) 25:30, 1967.

3. LOGAN, W. J. \& FREEMAN, J. M. - Pseudodegenerative disease due to diphenylhydantoin intoxication. Arch. Neurol. (Chicago) 21:631, 1969.

4. LUGARESI, E.; PAZZAGLIA, P. \& TASSINARI, C. A. - Differentiation of absence status", and "temporal lobe status". Epilepsia (Amsterdam) 12:77, 1971.

Departamento de Neuropsiquiatria e Psicologia Médica - Faculdade de Medicina - 14100 Ribeirão Preto, SP - Brasil. 